\title{
Therapeutic value of a new scarless intervention, ductoscopic papillomectomy, in patients with pathologic nipple discharge Ö Bender ${ }^{1}$, FL BalcR ${ }^{* 2}$, E Yüney ${ }^{1}$ and $\mathrm{H}_{\text {Akbulut }}{ }^{1}$
}

Address: ${ }^{1}$ Department of Surgery, OkmeydanR Training and Research Hospital, Istanbul, Turkey and ${ }^{2}$ Department of Surgery, jereflikoçhisar State Hospital, Ankara, Turkey

Email: FL BalcR* - omerbender@hotmail.com

* Corresponding author

from 6th International Symposium on the Intraductal Approach to Breast Cancer

Santa Monica, CA, USA. |9-2| February 2009

Published: 24 July 2009

BMC Proceedings 2009, 3(Suppl 5):SI5 doi:10.1/86/I753-656I-3-S5-SI5

This abstract is available from: http://www.biomedcentral.com/I753-656I/3/S5/SI5

(C) 2009 Bender et al; licensee BioMed Central Ltd.

\section{Background}

Efforts have been made to develop new methods to improve the diagnosis of intraductal lesions and their surgical removal. We evaluated the therapeutic value of a new scarless operation, endoscopic papillomectomy, (EP) in patients with pathologic nipple discharge (PND).

\section{Methods}

Breast ductoscopy was performed on 213 female patients with PND. These patients underwent a variety of appropriate ductoscopy-assisted (DA) endosurgical interventions, combined with cytologic examinations. Success was determined by recurrence of PND and by standard radiological examinations.

\section{Results}

Ductoscopy was successfully performed in 178 patients. Of these 178 patients, 34 had solitary papillomas (SP), 8 had multiple papillomas (MP), 19 had intraductal debris and 5 had ductal epithelial surface abnormality with positive cytology. Of the 34 polypoid lesions (cytology negative), 22 were excised endoscopically (endoscopic papillomectomy). Patients with MP underwent DAmicrodochectomy. These 42 patients ( 34 with SP, and 8 with MP) had histopathology results consistent with intraductal papillomas or papillomatosis. Five patients with positive cytology underwent DA-terminal ductal lobular unit excision after their histopathology reports showed had DCIS. Except in one patient, all discharges disappeared. After a mean \pm SD follow up time of $14.4 \pm$
5.2 months (range, 1-27 months), there were no recurrences of nipple discharge and no radiological results suggestive of malignancy. Thus, the therapeutic efficacy of EP in our study was $95.4 \%(21 / 22)$.

\section{Conclusion}

Ductoscopy is not only a diagnostic procedure, but is also therapeutic for breast papillomas. EP is a new scarless treatment option for patients with PND $(1,2)$. With technical improvements in ductoscopy and endoscopic sampling instruments, a greater degree of therapeutic efficacy will be achieved. 